\title{
False sense of safety by daily QTc interval monitoring during methadone IVPCA titration in a patient with chronic pain
}

This article was published in the following Dove Press journal:

Journal of Pain Research

21 May 2013

Number of times this article has been viewed

\section{Hector Miranda-Grajales Joy $\mathrm{HaO}$ \\ Ricardo A Cruciani}

Department of Pain Medicine and Palliative Care, Beth Israel Medical Center, New York, NY, USA
Correspondence: Ricardo A Cruciani 10 Union Square East, Suite 2Q-2R, Department of Pain Medicine and Palliative Care, Beth Israel Medical Center, New York, NY I0003, USA $\mathrm{Tel}+|2| 28441390$

Fax + I 2128446962

Email rcrucian@chpnet.org

\begin{abstract}
It has been proposed that some deaths attributed to methadone are related to prolongation of the QTc interval; however, there are no clear recommendations on electrocardiogram (ECG) monitoring in patients undergoing intravenous methadone infusion. This is a report on a patient receiving methadone intravenous patient-controlled analgesia titration for the treatment of chronic pain. Initially, her daily ECGs showed QTc intervals within normal limits; however, she experienced a rapid increase in QTc interval from $317 \mathrm{~ms}$ to $784 \mathrm{~ms}$ within a 24-hour period after methadone had been discontinued for excessive sedation. QTc interval greater than $500 \mathrm{~ms}$ is considered to be high risk for the fatal arrhythmia Torsades de Pointes. Daily ECGs did not detect a gradual increase in the QTc interval that would have alerted the medical staff of the need to decrease or stop the methadone before reaching a prolonged QTc interval associated with cardiotoxicity. In selected cases where aggressive methadone titration is required, more intensive monitoring, such as telemetry or ECG determinations every 12 hours, might help detect changes in QTc interval duration that might otherwise be missed by daily ECG determinations.
\end{abstract}

Keywords: methadone, QTc prolongation, opioids, opioid side effects, IVPCA methadone

\section{Background}

The use of methadone for the management of chronic pain has increased in the last decade, as has the number of the deaths attributed to its use. ${ }^{1}$ Methadone is a chiral mixture with a variable metabolization rate $^{2}$ that contributes to its unpredictable halflife (ranging between 15 and 150 hours), which can lead to drug accumulation and potential cardiac toxicity. ${ }^{1}$ Methadone and other opioids, including oxycodone, ${ }^{3}$ can block delayed potassium rectifying currents $\left(\mathrm{I}_{\mathrm{kr}}\right)$, thus interfering with the repolarization of the conductive tissue of the heart ${ }^{4}$ and predisposing to Torsade de Pointes (TdP), a fatal ventricular arrhythmia. On electrocardiogram (ECG), prolonged depolarization manifests as QTc interval prolongation. ${ }^{5}$ An acceptable QTc interval upper limit has been proposed to be 430 and $450 \mathrm{~ms}$ for males and females, ${ }^{6}$ respectively, while values beyond $500 \mathrm{~ms}$ are considered to be high risk for TdP irrespective of sex. ${ }^{6}$

Although the use of intravenous (IV) methadone in the terminally ill population is considered to be safe, ${ }^{7}$ and the QTc prolongation reported by Kornick et al was attributed to the preservative chlorobutanol, ${ }^{8}$ many reports suggest that methadone itself may prolong the QTc interval in a dose-dependent manner. ${ }^{4}$ Furthermore, coadministration of certain medications may increase the risk of cardiotoxicity, for example, drugs that have the potential to prolong the QTc interval, ${ }^{9}$ such as certain antibiotics or antiarrhythmic agents, or drugs that may compete with methadone as substrates for the cytochrome P450 isoenzymes $3 \mathrm{~A} 4,2 \mathrm{D} 6$, and $2 \mathrm{~B} 6,{ }^{10}$ such as certain antidepressants, resulting in 
elevated methadone plasma levels. To address the risk of cardiotoxicity, some authors have advocated serial ECGs to monitor the QTc interval duration, ${ }^{11}$ but the recommendations on frequency of monitoring and medication dose at which the ECG should be done are controversial' 12 and range from "ECG is never necessary" to perform ECG "in every patient."13

\section{Objective}

To promote awareness that daily ECG monitoring during IV patient-controlled analgesia (PCA) with methadone may not be sufficient to anticipate a rapid prolongation of the QTc interval.

\section{Methods and findings}

The patient was a 50-year-old woman with chronic abdominal pain for over 10 years due to lupus vasculitis who during hospitalization for opioid rotation, experienced QTc prolongation beyond $500 \mathrm{~ms}$ during rapid IV methadone titration in less than 24 hours. The patient's pain had not been managed to satisfaction as an outpatient, and admission for IV opioid titration was recommended. At the time of admission to the Pain Service Inpatient Unit, Beth Israel Medical Center, New York, NY, USA, the patient's medications included morphine sulfate $150 \mathrm{mg}$ intramuscular (IM) every 4 hours and meperidine 75 mg IM every 8 hours, and her pain score was 10/10. During hospitalization, the patient underwent trials with intravenous patient controlled analgesia (IVPCA) hydromorphone, morphine, and fentanyl, which did not alleviate the pain or cause significant side effects and had to be discontinued. Afterwards, the patient received IV methydlprednisolone and ketamine infusion, and both were ineffective. After a baseline ECG that showed a QTc interval of $449 \mathrm{~ms}$, an IVPCA methadone trial was initiated. The 12-lead ECG was obtained with a MAC 5000 machine (GE Medical Systems, Milwaukee, WI, USA). The QT interval was measured manually by a board-certified cardiologist. The interval was corrected for heart rate using the Bazett formula: ${ }^{6}$

$$
\mathrm{QTc}=\mathrm{QT} / \mathrm{Sqrt}[\mathrm{RR}]
$$

QTc prolongation was defined as intervals longer than $430 \mathrm{~ms}$ for males and $450 \mathrm{~ms}$ for females. ${ }^{14}$ During the first 7 days of methadone IVPCA titration, the QTc interval duration ranged from 416 to $449 \mathrm{~ms}$ (Table 1). On the morning of day 8, the QTc interval was $317 \mathrm{~ms}$ (Table 1). That night, due to excessive sedation, the IVPCA methadone was discontinued, so the patient received only $184 \mathrm{mg}$ during the 24-hour period. During this episode, the patient was easily aroused; oriented to self, time, and space; had stable vital signs (BP
134/82; HR 62; RR 12); and had no evidence of arrhythmia (although an ECG was not done). The next morning, a repeat ECG showed a QTc interval of $784 \mathrm{~ms}$ (12 hours after the methadone IVPCA had been discontinued). At that point, the sedation was resolved, there was no evidence of withdrawal symptoms, and the electrolytes were within the normal range $\left(\mathrm{K}^{+} 4.3, \mathrm{Ca}^{2+}\right.$ 9.3, $\mathrm{Mg}^{2+}$ 2.0, aspartate aminotransferase (ALT) 17 , alanine aminotransferase (AST) 16 for a reference range of $3.7-5.2 \mathrm{mEq} / \mathrm{L}, 8.5-10.9 \mathrm{mg} / \mathrm{dL}, 1.7-2.2 \mathrm{mg} / \mathrm{dL}, 8-37$ $\mathrm{IU} / \mathrm{L}$, and 10-34 IU/L respectively). The patient remained on nortriptilyne $25 \mathrm{mg}$ in the morning and afternoon and 50 at bed time (plasma level of 81 for a therapeutic range of $70-170 \mathrm{ng} / \mathrm{mL}$ ), and baclofen $10 \mathrm{mg}$ every 8 hours that she had been taking at the same dose for several months before this admission. It is worth noting that no new medications that could prolong the QTc interval or interfere with methadone metabolism were initiated at this admission, (for a list of medications that can prolong the QTc interval, visit http:// www.torsades.org). Twenty-four hours later, the QTc interval duration was $476 \mathrm{~ms}$, and the patient reported a pain score of $8 / 10$. At this time, methadone was resumed as an oral formulation at half the dose of that before discontinuation (30 mg three times a day), which is a dose that had not caused significant QTc interval prolongation a few days earlier. In addition, the patient received hydromorphone 8-16 $\mathrm{mg} \mathrm{IV}$ every 3 hours as needed to provide additional pain relief and to control withdrawal symptoms. This combination of medications provided inadequate pain relief, as the patient reported pain scores ranging from $6 / 10$ to $10 / 10$.

On day 15, in view of the poor response obtained with IV and oral opioids (the patient continued to report pain scores of 10/10), methadone was discontinued, and a trial of neuroaxial analgesia that included hydromorphone, bupivacaine, clonidine, baclofen, and midazolam was conducted. At day 21, the patient continued reporting pain scores that ranged between $8 / 10$ and $10 / 10$, and the neuroaxial analgesia trial was discontinued. At this point, oral methadone was titrated, up to $30 \mathrm{mg}$ four times a day, and the patient also received transdermal fentanyl $300 \mu \mathrm{g}$ /hour every 72 hours (dose based on the IVPCA fentanyl trial that the patient had had earlier during this hospitalization). Hydromorphone 8-16 mg every 3 hours as needed was continued to manage breakthrough pain and withdrawal symptoms. On day 24, the patient was discharged on methadone and transdermal fentanyl, with the addition of meperidine IM and morphine IM, which the patient had used for many years, but now at lower doses and with longer intervals between administrations. At discharge, her pain score was 4/10 and the QTc interval 
Table I Methadone dose over time and daily ECG

\begin{tabular}{|c|c|c|c|c|}
\hline \multirow[t]{2}{*}{ Day of IVPCA } & \multicolumn{3}{|l|}{ Methadone } & \multirow{2}{*}{$\begin{array}{l}\text { QTc interval } \\
\text { duration (ms) }\end{array}$} \\
\hline & $\begin{array}{l}\text { Total methadone } \\
\text { oral dose } \\
(\mathrm{mg} / 24 \mathrm{~h})\end{array}$ & $\begin{array}{l}\text { IVPCA methadone dose } \\
\text { (continuous rate plus demand, } \\
\mathrm{mg} / 24 \mathrm{~h} \text { ) and conversion } \\
\text { to PO equivalency dose } \\
(\mathrm{IV} \text { to } \mathrm{PO} \text { conversion factor }=2)\end{array}$ & $\begin{array}{l}\text { Total methadone dose } \\
\text { in } \mathrm{PO} \text { equivalent } \\
(\mathrm{mg} / 24 \mathrm{~h})\end{array}$ & \\
\hline Day I & 40 & $28.8 \times 2=57.6$ & 97.6 & 449 \\
\hline Day 2 & 60 & $58.8 \times 2=117.6$ & 177.6 & 445 \\
\hline Day 3 & 60 & $94.8 \times 2=189.6$ & 249.6 & 430 \\
\hline Day 4 & 60 & $151.6 \times 2=303.2$ & 363.2 & 426 \\
\hline Day 5 & 60 & $121 \times 2=242$ & 302 & 416 \\
\hline Day 6 & 60 & $126.9 \times 2=253.8$ & 313.8 & 420 \\
\hline Day 7 & 60 & $137.3 \times 2=274.6$ & 334 & 429 \\
\hline Day 8 & 60 & $62 \times 2=124(12 h)$ & 184 & 317 \\
\hline Day 9 & 20 & - & 20 & 784 \\
\hline Day 10 & 120 & - & 120 & 476 \\
\hline Day II & 120 & - & 120 & 486 \\
\hline Day 12 & 120 & - & 120 & 477 \\
\hline Day 13 & 120 & - & 120 & 495 \\
\hline Day 14 & 120 & - & 120 & 471 \\
\hline Day 15 & None & - & 0 & 485 \\
\hline Day 16 & None & - & 0 & 432 \\
\hline Day 17 & None & - & 0 & 451 \\
\hline Day 18 & None & - & 0 & 418 \\
\hline Day 19 & None & - & 0 & 437 \\
\hline Day 20 & None & - & 0 & 421 \\
\hline Day 21 & 30 & - & 30 & 404 \\
\hline Day 22 & 60 & - & 60 & 443 \\
\hline Day 23 & 90 & - & 90 & 448 \\
\hline Day 24 & 90 & - & 90 & 467 \\
\hline
\end{tabular}

Notes: QTc duration versus total methadone dose. The first ECG was done to obtain a QTc interval duration baseline. Thereafter, daily ECGs were obtained to monitor the duration of the QTc while the IVPCA methadone titration was conducted. The total methadone dose was defined as the addition of the constant infusion rate, the demand dose, and the IV equivalent oral dose, in 24-hour periods. The methadone IV to oral conversion ratio was I:2.

Abbreviations: ECG, electrocardiogram; IV, intravenous; PCA, patient-controlled analgesia; PO, per oral.

was $437 \mathrm{~ms}$. We recognize that meperidine IM long-term use is not recommended, and the potential buildup of the metabolite normeperidine can cause seizures. However, the patient expressed anxiety at the prospect of discontinuing this medication, which she had been taking for many years without experiencing significant side effects. Therefore, we developed a plan to gradually switch from the use of injectable meperidine to injectable morphine, with eventual plan to transition to oral medications. After discharge, the patient was evaluated weekly in an outpatient setting for 1 month, at the end of which her pain score was 4/10, and the QTc interval was $372 \mathrm{~ms}$. Four months later, the overall injectable mediations had been reduced by an additional $25 \%$ and her QTc interval duration was $410 \mathrm{~ms}$.

\section{Discussion}

An ECG is a good screening tool for cardiac arrhythmias; ${ }^{14}$ however, in this case, daily ECGs were not sufficient to guide dosing during rapid methadone titration as a gradual prolongation of the QTc interval was not observed. Instead, the QTc interval jumped from what is considered to be low risk for cardiotoxicity to over $700 \mathrm{~ms}$ in less than 24 hours, putting the patient at high risk for fatal arrhythmias such as TdP. Since the methadone was preservative-free, and medications that can be substrates of the cytochrome $\mathrm{P} 450$ isoenzymes $3 \mathrm{~A} 4,2 \mathrm{D} 6$, and $2 \mathrm{~B} 6$, or those that can block the $\mathrm{I}_{\mathrm{kr}}$, were not initiated during this hospitalization, it is likely that the observed prolongation was due to a dose-dependent effect of methadone on the QTc interval caused by drug accumulation. In this report, daily ECGs did not detect a gradual increment of the QTc interval duration that would have guided clinical decisions to either decrease or stop the drug before the QTc interval exceeded $500 \mathrm{~ms}$. Therefore, while daily ECGs may be useful, this should not be the only method used to guide clinical decisions regarding dose adjustments of methadone, as a normal QTc interval can give a false sense of safety. 
Telemetry monitoring or ECG determinations every 12 hours should be considered in cases in which aggressive titration of IV methadone is elected. However, since methadone plasma levels were not measured in this case, the conclusions of this report cannot be generalized.

\section{Disclosure}

Ricardo A Cruciani is on the speaker board for ENDO, Covidien, and Pfizer; has been coinvestigator in research funded by Ameritox; has organized CME courses funded by Grupo Ferrer; and has been in the advisory board for Depomed and Janssen Pharmaceuticals. The authors report no other conflicts of interest in this work.

\section{References}

1. Webster LR, Cochella S, Dasgupta N, et al. An analysis of the root causes for opioid-related overdose deaths in the United States. Pain Med. 2011;12 Suppl 2:S26-S35.

2. Eap CB, Crettol S, Rougier JS, et al. Stereoselective block of hERG channel by (S)-methadone and QT interval prolongation in CYP2B6 slow metabolizers. Clinic Pharmacol Ther. 2007;81(5):719-728.

3. Daniell HW. Torsades-de-Pointes associated with Taku-Tsubo cardiomyopathy following greatly reduced oxycodone use in an elderly woman. $J$ Opioid Manag. 2011;7(2):155-159.

4. Ansermot N, Albayrak O, Schläpfer J, et al. Substitution of (R,S)methadone by (R)-methadone: impact on QTc interval. Arch Intern Med. 2010;170(6):529-536.
5. Krantz MJ, Lewkowiez L, Hays H, Woodroffe MA, Robertson AD, Mehler PS. Torsade de pointes associated with very-high-dose methadone. Ann Intern Med. 2002;137(6):501-504.

6. Moss AJ, Zareba W, Benhorin J, et al. ISHNE guidelines for electrocardiographic evaluation of drug-related QT prolongation and other alterations in ventricular repolarization: task force summary. A report of the Task Force of the International Society for Holter and Noninvasive Electrocardiology (ISHNE), Committee on Ventricular Repolarization. Ann Noninvasive Electrocardiol. 2001;6:333-341.

7. Shaiova L, Berger A, Blinderman CD, et al. Consensus guideline on parenteral methadone use in pain and palliative care. Palliat Support Care. 2008;6(2):165-176.

8. Kornick CA, Kilborn MJ, Santiago-Palma J, et al. QTc interval prolongation associated with intravenous methadone. Pain. 2003; 105(3):499-506.

9. Cruciani RA, Sekine R, Homel P, et al. Measurement of QTc in patients receiving chronic methadone therapy. J Pain Symptom Manage. 2005;29(4):385-391.

10. Pelet A, Favrat B, Cavassini M, Eap CB, Besson J, Monnat M. Usefulness of methadone plasma concentration measurement in patients receiving nevirapine or efavirenz. Am J Drug Alcohol Abuse. 2011;37(4):264-268.

11. Krantz MJ, Martin J, Stimmel B, Mehta D, Haigney MC. QTc interval screening in methadone treatment. Ann Intern Med. 2009; 150(6):387-395.

12. Girgis G. Concerns about consensus guidelines for QTc interval screening in methadone treatment. Ann Intern Med. 2009;151(3):217-218.

13. Cruciani RA. Methadone: to ECG or not to ECG ... That is still the question. J Pain Symptom Manage. 2008;36(5):545-552.

14. Roden DM. Drug-induced prolongation of the QT interval. $N$ Engl $J$ Med. 2004;350(10):1013-1022.
Journal of Pain Research

\section{Publish your work in this journal}

The Journal of Pain Research is an international, peer-reviewed, open access, online journal that welcomes laboratory and clinical findings in the fields of pain research and the prevention and management of pain. Original research, reviews, symposium reports, hypothesis formation and commentaries are all considered for publication.

\section{Dovepress}

The manuscript management system is completely online and includes a very quick and fair peer-review system, which is all easy to use. Visit http://www.dovepress.com/testimonials.php to read real quotes from published authors. 